\title{
A remarkable new species of the rove beetle genus Anthobium Leach, 1819 from Eocene Baltic amber (Coleoptera, Staphylinidae, Omaliinae)
}

\author{
Alexey V. Shavrin', Shûhei Yamamoto² \\ I Institute of Life Sciences and Technologies, Daugavpils University, Vienibas 13, Daugavpils, LV-5401, Latvia \\ 2 The Hokkaido University Museum, Kita 8, Nishi 5, Kita-ku, Sapporo 060-0808, Japan \\ Corresponding author: Alexey V. Shavrin (ashavrin@hotmail.com)
}

Academic editor: J. Klimaszewski | Received 5 May 2020 | Accepted 21 August 2020 | Published 5 October 2020

http://zoobank.org/9471AA9B-4FED-45A4-800F-B79B9AA39949

Citation: Shavrin AV, Yamamoto S (2020) A remarkable new species of the rove beetle genus Anthobium Leach, 1819 from Eocene Baltic amber (Coleoptera, Staphylinidae, Omaliinae). ZooKeys 973: 89-101. https://doi.org/10.3897/ zookeys. 973.53940

\begin{abstract}
An unusual new omaliine species, Anthobium alekseevi sp. nov., is described and illustrated from Eocene Baltic amber, tentatively placed in the megadiverse genus Anthobium Leach, 1819. A new monotypic species-group is established. The new species can easily be distinguished from other species of the genus by the larger body, shape of the subrectangular pronotum, and the presence of a median carina on the prosternum and large, subtriangular tooth on the inner side of each mesotibia, likely exhibiting a peculiar sexual dimorphism in the male. Based on the study of the specimen with support of microtomographic images, a brief comparative analysis of a new species with described extant species of Anthobium is provided.
\end{abstract}

\section{Keywords}

Anthobium, Anthophagini, fossil, Omaliini, palaeontology, sexual dimorphism, $\mathrm{x}$-ray micro-CT

Copyright A.V. Shavrin, S.Yamamoto. This is an open access article distributed under the terms of the Creative Commons Attribution License (CC BY 4.0), which permits unrestricted use, distribution, and reproduction in any medium, provided the original author and source are credited. 


\section{Introduction}

The rove beetles of the subfamily Omaliinae, with about 1700 species in 118 extant and 14 extinct genera, are distributed in northern temperate areas, with greatest diversity in the Holarctic region. Omaliines are common in various types of biotopes. An overwhelming number of species are hygrophiles, and they can be found near swamps, banks of rivers, mountain streams at high elevations, etc. Most species are predators of small invertebrates or are sapro- and mycophagous, and some species are even pollenfeeders (e.g. Amphichroum Kraatz, 1858).

The fossil history of Omaliinae was briefly discussed by Chatzimanolis (2018) and in more detail by Shavrin and Yamamoto (2019). Several extinct taxa were described based on impressions from the Jurassic (Tikhomirova 1968; Ryvkin 1985; Cai and Huang 2013), Cretaceous (Ryvkin 1990), or Cenozoic eras (Scudder 1900). Recently, seven species in three tribes of Omaliinae were reported from Eocene Baltic amber (Zanetti et al. 2016; Shavrin and Yamamoto 2019), but only one of them, Geodromicus balticus Shavrin \& Yamamoto, 2019, belongs to the tribe Anthophagini.

Due to the poor visibility of several main details of the body, the single specimen of a possible omaliine, as an inclusion within a piece of the Baltic amber from the collection of V. Alekseev (Kaliningrad), was difficult to attribute to any taxon, and therefore it was not included in our last study on fossil omaliines (Shavrin and Yamamoto 2019). However, we recently obtained microtomographic images of this specimen, which allowed us not only to ascertain that it belongs to the subfamily Omaliinae but even to assign to the tribe Anthophagini. Based on the combination of morphological characters such as the general shape of the convex body, shapes of two preapical palpomeres of maxillary palps, the presence of postocular ridge, the shape of gular structures, located close together, the structure of the pronotum with deep mediolateral pits, and explanate lateral portions, this species clearly belongs to the Anthobium group of genera (e.g. Campbell 1987; Shavrin and Smetana 2017). This group contains 11 extant genera distributed in the Holarctic region: Acidota Stephens, 1829, Anthobioides Campbell, 1987, Anthobiomorphus Shavrin \& Smetana, 2020, Anthobium Leach, 1819, Arpedium Erichson, 1839, Camioleum Lewis, 1893, Caucanthobium Assing, 2018, Deinopteroloma Jansson, 1946, Deliphrosoma Reitter, 1909, Deliphrum Erichson, 1839, and Olophrum Erichson, 1839. In addition, this group contains two extinct genera, which were described on impressions: Mesozoic Mesodeliphrum Ryvkin, 1990 from Turga, Transbaikal Russia (Ryvkin 1990) and Sinanthobium Cai \& Huang, 2013 from the Middle Jurassic Jiulongshan Formation at Daohugou, Inner Mongolia, China (Cai and Huang 2013). Based on the shape of the body, features of sculpture of the forebody, the presence of long grooves in front of the ocelli (tentorial pits), the proportions of palpomeres of the maxillary palp, and the structure of the setation of the meso- and metatibia, the new species can be tentatively attributed to the megadiverse genus Anthobium. The senior author is currently actively exploring this genus and has published already several papers on a few established groups of species from Eastern Palaearctic Region (Shavrin and Smetana 
2017, 2018, 2019; Shavrin 2020). To date, 70 species (plus four nomina dubia) of the genus are known from the Holarctic Region: 19 species from the western and 38 from the eastern Palaearctic regions, and 13 species from the Nearctic Region. The revision of the entire genus is still in progress and the extant taxonomic diversity has not yet been fully revealed, as several groups and species are still awaiting to be described and its phylogeny thoroughly investigated. Meanwhile, despite some morphological differences from other known taxa, the new species is nevertheless assigned to Anthobium, as a separate group of species. The new species represents the second species of Anthophagini known from Eocene Baltic amber. The obtained palaeontological data will undoubtedly be useful in constructing possible phylogenetic relationships in the Anthobium group of genera in the future.

\section{Materials and methods}

The studied material is housed in the private collection of Vitalii I. Alekseev (Kaliningrad, Russia) and eventually will be deposited in Borissiak Paleontological Institute of the Russian Academy of Sciences, Moscow, Russia (PIN). This piece of amber was collected by net in the Baltic Sea (Kaliningrad Area, Russia) in the beginning of 2017. It was polished, embedded in a block of GTS-polyester resin, and polished again according the method of Hoffeins (2001).

All measurements are given in millimeters and were made with a stereoscopic microscope equipped with an ocular micrometer. Measurements were made from the dorsal side of the specimen except for ocular length and width of the abdomen which were made from the ventral side. Measurement of the total length of the body was difficult to do because of the specimen's orientation within the amber piece; the resulting approximate values are marked with " $>$ ". The type labels are cited in inverted commas and separated from each other by a comma, different lines in labels are separated with '|'; explanations of the type labels are given in square brackets, necessary notes within the label are given in angle brackets.

The specimen was examined using a Nikon SMZ 745T stereomicroscope. A Sony Alpha DSLR-A300digital camera was used for photographs of amber, habitus, and its details. Micro-CT observations of the specimens were conducted at the Daugavpils University (Daugavpils, Latvia) using Zeiss Xradia 510 Versa system. Scans were performed with a polychromatic x-ray beam at an energy of $40 \mathrm{kV}$ and power of $3 \mathrm{~W}$. Sample-detector distance was set to $17.6 \mathrm{~mm}$ and source to sample distance $32.6 \mathrm{~mm}$. Tomographic slices were generated from 3001 rotation steps through a 360-degree rotation, using a $4 \times$ objective, and exposure time during each projection was set to $3 \mathrm{~s}$. Acquired images were binned $(2 \times 2 \times 2)$ giving a voxel size of $4.3 \mu \mathrm{m}$. Images were imported into Dragonfly PRO (ver. 4.1) software platform for interactive segmentation and $3 \mathrm{D}$ visualization. Prior to the full scan a 23 -minute warmup scan was conducted with the same scan parameters except rotation steps which had been reduced to 201 and exposure time which was reduced to $1 \mathrm{~s}$. 


\title{
Systematic palaeontology
}

\author{
Order Coleoptera Linnaeus, 1758 \\ Family Staphylinidae Latreille, 1802 \\ Subfamily Omaliinae MacLeay, 1825 \\ Tribe Anthophagini Thomson, 1859
}

\section{Genus Anthobium Leach, 1819}

Type species. Omalium atrocephalum Gyllenhal (= Silpha melanocephalum sensu Marsham), for details see Herman (2001).

\section{Anthobium alekseevi group of species}

Diagnosis. Body medium-sized; forebody convex, shiny; apical segment of maxillary palp twice as long as preceding segment; anterior angles of subrectangular pronotum slightly protruded anteriad, mediobasal third of pronotum with oval impression; lateral edges of pronotum without crenulation; prosternum with distinct median carina; surface of elytra without elevations; inner side of each mesotibia with large tooth in middle.

Species included. $\dagger$ Anthobium alekseevi sp. nov.

Remarks. Anthobium alekseevi sp. nov. differs from the remaining species of the genus by the larger body, the shape of the subrectangular pronotum, the presence of distinct median carina on the prosternum, and the presence of a large median tooth on the inner side of the mesotibia.

\section{$\dagger$ Anthobium alekseevi Shavrin \& Yamamoto, sp. nov.}

http://zoobank.org/A1797770-BE2C-4B9A-99B1-5D93D54B7943

Figures 1-19

Type material examined. Holotype: male, complete specimen as inclusion in a piece of small yellow Baltic amber, $11.0 \mathrm{~mm} \times 0.7 \mathrm{~mm} \times 0.5 \mathrm{~mm}$ in size (Figs 1,2), with glued small paper on side of an amber labeled "AWI148" and additional labels within a plastic envelope: "AWI-148 | Omaliinae | gen. nov. | (mesotibia!)" <handwritten>, "HOLOTYPE $\mid$ Anthobium | alekseevi sp. nov. | Shavrin A. \& Yamamoto S. des. 2020" $<$ red rectangular label, printed $>$ (PIN).

Preservation. The specimen is poorly visible because it is partially covered with white microbubbles, and some details of the structure of the body are not visible: head, median portion of pronotum and scutellum, ventral side of the body and abdomen (Figs 1,2). The basal part of the abdomen ventrally is covered by left hind wing.

Locality and horizon. Baltic amber from Kaliningrad Area, westernmost Russia; mid-Eocene (ca $44 \mathrm{Ma}$; Wappler 2005). 


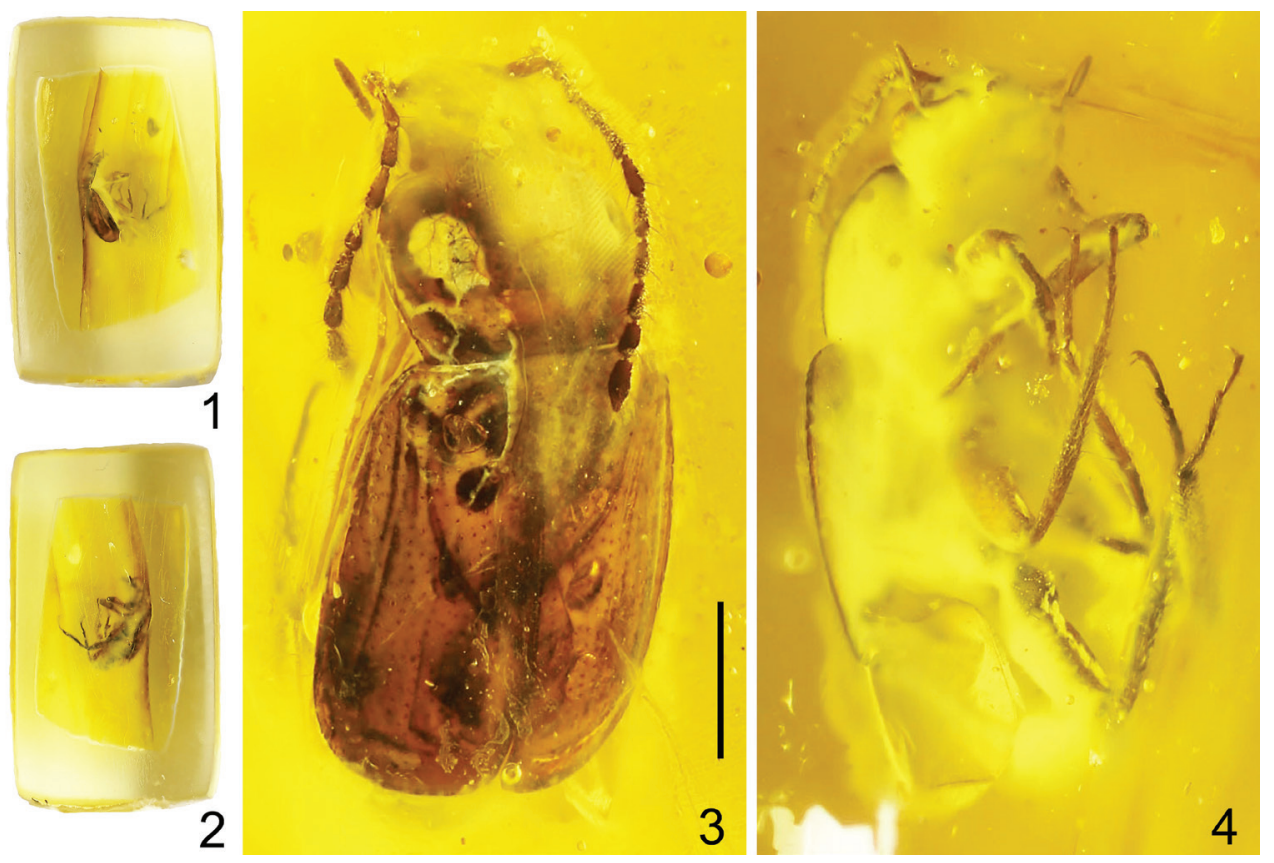

Figures 1-4. Anthobium alekseevi sp. nov. I, 2 amber specimen with inclusion $\mathbf{3}$ habitus, dorsal view 4 habitus, dorsoventral view. Scale bar: $1.0 \mathrm{~mm}(\mathbf{3}, \mathbf{4})$.

Description. Measurements: maximum width of head including eyes: 1.30; length of head (from base of labrum to neck constriction along head midline in dorsal view): 0.75; ocular length: 0.40 ; length $\times$ width of segments III and IV of maxillary palpi: III: $0.15 \times 0.10$, IV: $0.30 \times 0.10$; length of antenna: 2.70 ; length of pronotum: 1.35 ; maximum width of pronotum: 1.75 ; sutural length of elytra from apex of scutellum to posterior margin of sutural angle: 2.60; length of elytron from basal to apical margin: 2.95; maximum width of elytra: 2.30; length of metatibia: 1.60; length of metatarsus: 0.80 ; maximum width of abdomen (at segment IV): 2.10 ; total length (from anterior margin of clypeus to apex of abdomen): -5.40 .

Body oblong, moderately wide, shiny (Fig. 3); body laterally as in Figures 5, 6, 9, and 10; body dorsolaterally as in Figure 4; body ventrally as in Figures 11 and 12; forebody as in Figure 14. Body and antennomeres 3-11, brown; legs and mouthparts reddish-brown; antennomeres 1 and 2 yellow-brown.

Head transverse (Figs. 15, 16), 1.7 times as wide as long; anterior portion of frons with obliquely elevated supra-antennal prominences and moderately wide impressions behind them; middle portion slightly elevated, with distinct, deep, narrow dorsal tentorial pits (grooves) in front of ocelli, diagonally stretching apicad to level of middle length of eyes; basal portion with distinct, narrow impression between ocelli; postocular ridge distinct, acute, located relatively close to posterior margin of eye, if see laterally (Figs 5, 9 , 18). Eyes large, convex. Ocelli large, situated at about level of postocular ridges; distance between ocelli slightly shorter than distance between ocellus and posterior margin of 


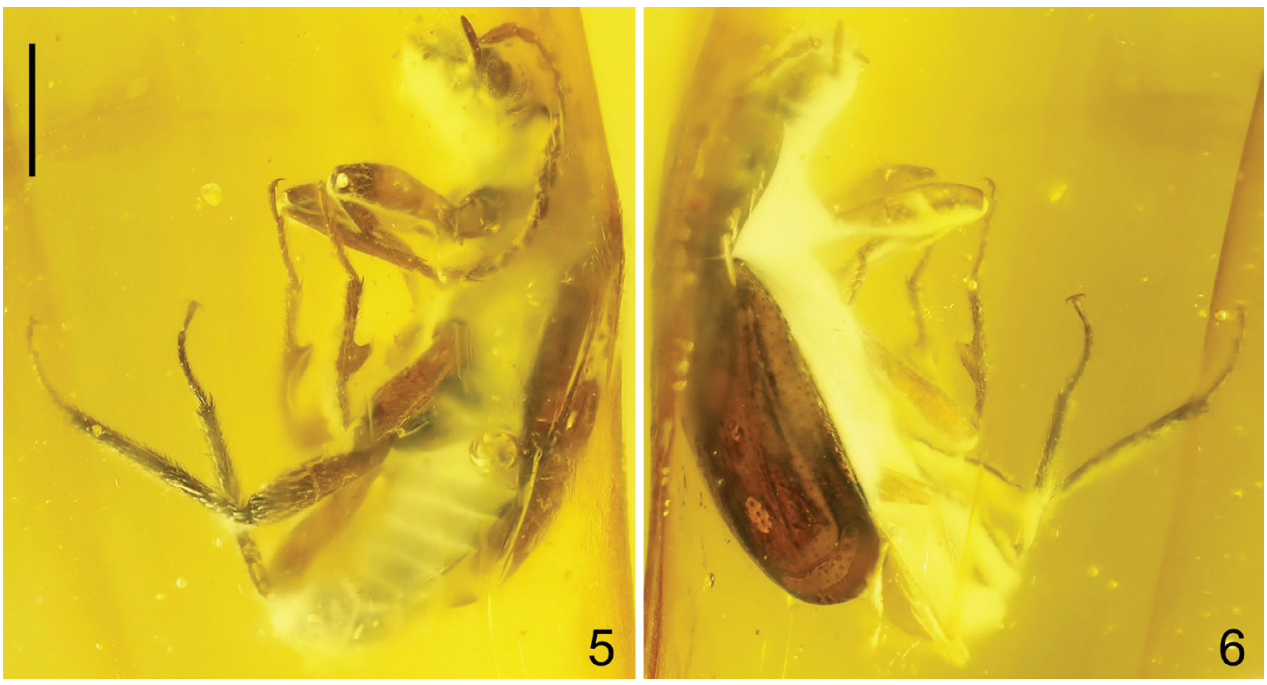

Figures 5, 6. Anthobium alekseevi sp. nov., habitus (lateral view). Scale bar: $1.0 \mathrm{~mm}$.

eye (Figs 15, 16). Labrum wide, transverse. Mentum and labium narrow, with distinctly elongate apical labial palpomere (Fig. 12). Preapical segment of maxillary palpus moderately long, 1.5 times as long as wide, and as wide as apical segment; apical segment about twice as long as preceding segment, from middle gradually narrowing toward apex (Figs $5,11,18)$. Gular sutures with shortest distance located at level of posterior third of eyes (Fig. 12). Antenna moderately short, exceeding apical third of elytra, with elongate antennomeres 5-10 and long preapical setae, antennomeres 3-11 covered by dense pubescence; basal antennomere moderately wide, 1.5 times as long as 2, antennomere 2 ovoid, about twice as long as wide and slightly shorter than 3, 3 and 4 as wide as 2, 5-7 slightly shorter than 4, 8 and 9 slightly shorter than 7, 10 distinctly shorter than 9, apical antennomere 1.6 times as long as 10, from middle gradually narrowed toward apex (Fig. 3).

Pronotum subrectangular, 1.2 times as wide as long, 1.3 times as wide as head, widest in middle, evenly rounded both anteriad and posteriad (Fig. 14); apical margin rounded, distinctly narrower than posterior margin; anterior angles widely rounded, slightly protruded anteriad; posterior angles obtuse; lateral edges bordered, without visible crenulation; disc with middle portion widely elevated, with indistinct, wide, semioval impression on mediobasal third, and lateral portions moderately wide, slightly explanate, each with deep pit in middle (Fig. 16). Laterobasal and basal portions of pronotum with dense and fine punctation (Fig. 3). Pronotal hypomeron and postcoxal process well developed; intercoxal process elongate and moderately wide; prosternum with distinct median carina (Figs 11, 18). Scutellum large and wide, with rounded apex. Metaventrite wide, convex.

Elytra convex, slightly longer than wide, about twice as long as pronotum, indistinctly widened in middle, reaching basal margin of abdominal tergite VI, with widely rounded apical margins (Fig. 17); shoulders of elytra rounded; lateral portions narrow, 


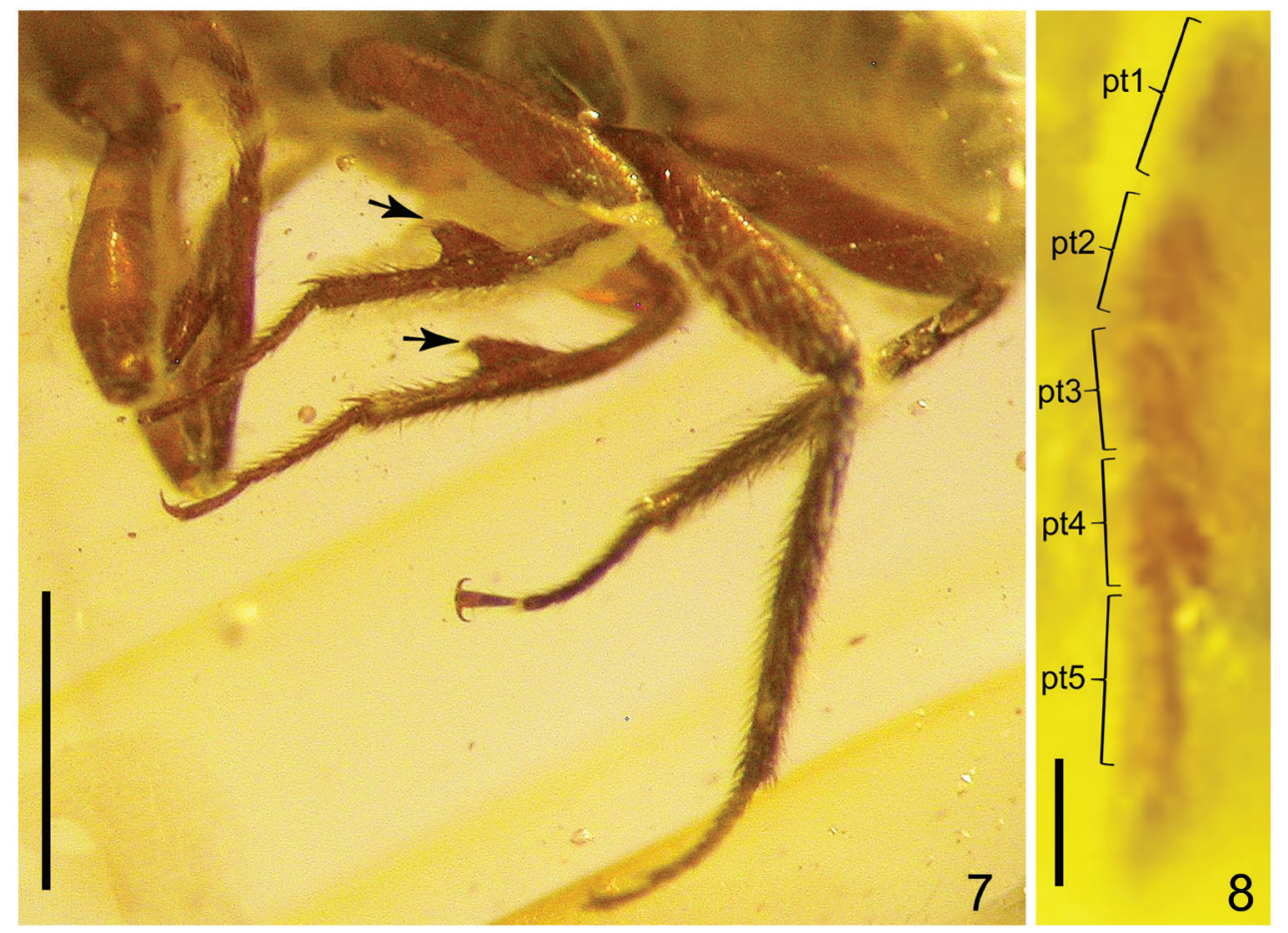

Figures 7, 8. Anthobium alekseevi sp. nov. 7 legs 8 protarsus. Scale bars: $1.0 \mathrm{~mm}(\mathbf{7}) ; 0.1 \mathrm{~mm}(\mathbf{8})$. Abbreviations: pt $1-\mathrm{pt} 5=$ protarsomeres $1-5$.

explanate; surface of elytra without visible elevations. Punctation sparse and moderately small, each elytron with longitudinal rows of vague serial punctures in middle (Fig. 3). Hind wings fully developed.

Legs long (Fig. 7); procoxae wide, protruding ventrad, contiguous; mesocoxae large, convex; metacoxae strongly transverse; pro-, meso-, and metatrochanter relatively narrow, elongate (Figs 11, 12); all femora widest at about middle, profemora slightly wider than meso- and metafemora; pro- and mesotibiae about as long as femora; protibiae covered with dense long setae; protarsomeres $1-5$ as in Fig. 8; mesotibiae indistinctly curved in middle, inner side of each mesotibia with large and wide subtriangular, finshaped tooth in middle (Fig. 7, arrows); meso- and metatibiae covered by very dense, long and strong setae (including apex of tooth on each mesotibia); metatibiae with additional very long setae; metatibiae distinctly longer than metafemora, slightly widened in about middle, covered by dense, strong and long setae, with a few additional spines around apical margin; all tarsi 5-segmented, all tarsi combined shorter than tibia; tarsomeres 1-4 with long and dense lateral setation; apical tarsomere about as long as preceding three tarsomeres together; tarsal claws simple, without modifications (Fig. 7).

Abdomen distinctly narrower than elytra (Fig. 17), from segment IV significantly narrowing apicad (Fig. 11); abdominal segment IX elongate. Abdomen ventrally as in Figures 11 and 12. 


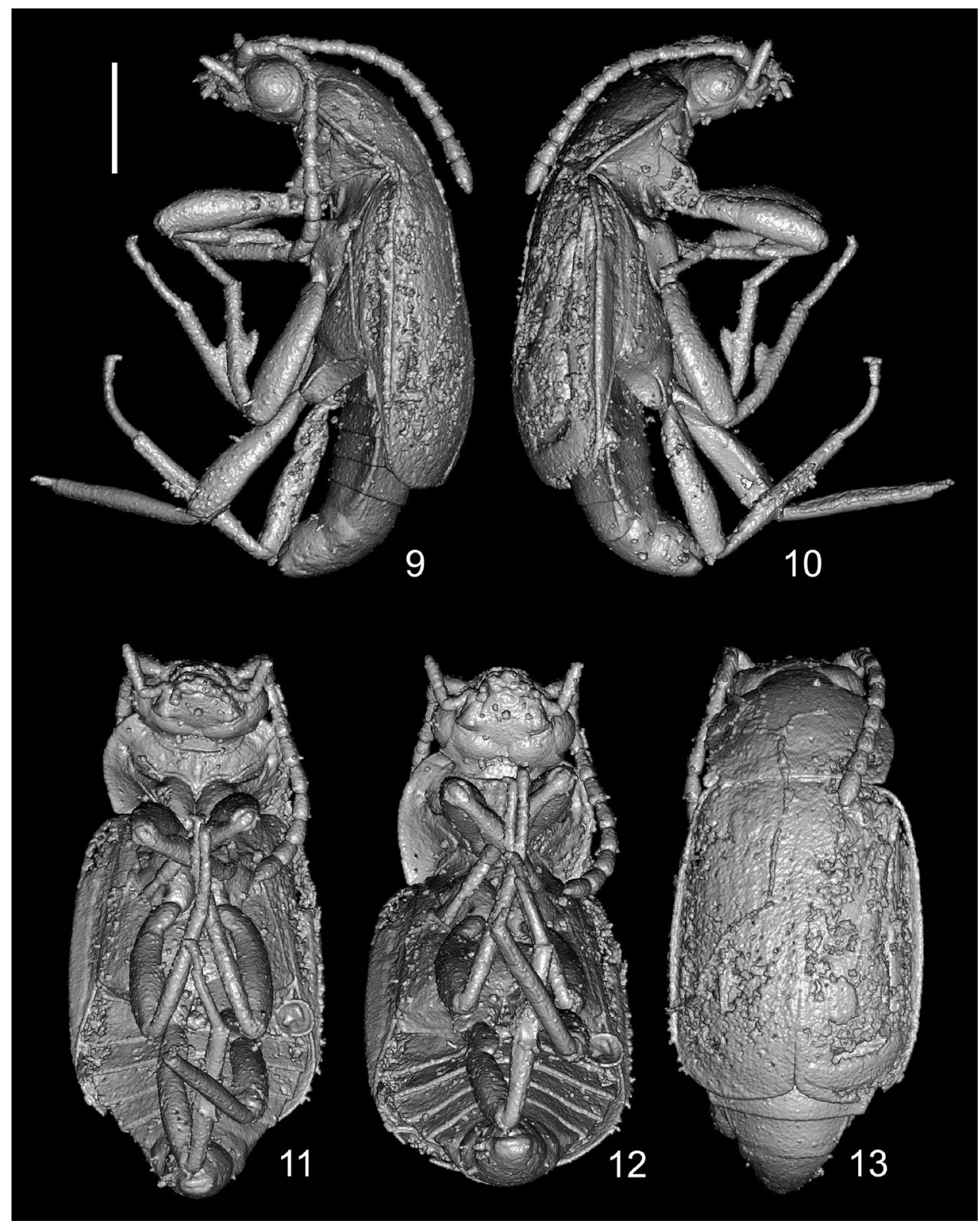

Figures 9-I3. Habitus of Anthobium alekseevi sp. nov. 9, I0 lateral view I I, I 2 ventral view I 3 dorsal view. Scale bar: $1.0 \mathrm{~mm}$.

Male. Protarsomeres 1-4 distinctly wide, with very long lateral setae (Fig. 8). Apical margin of abdominal tergite VIII rounded (Fig. 17). Apical margin of sternite VIII sinuate (Fig. 12).

Female unknown. 


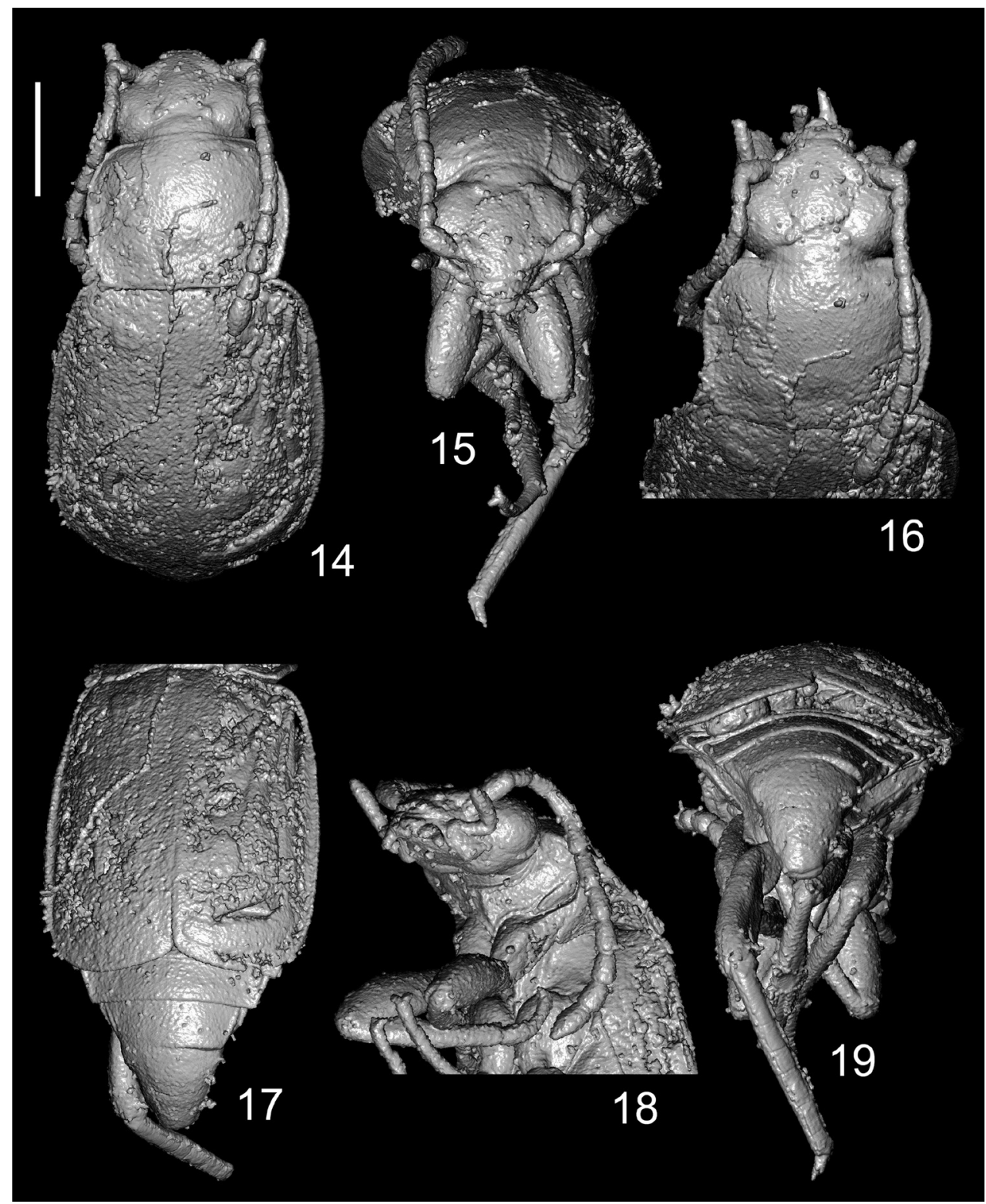

Figures 14-19. Anthobium alekseevi sp. nov. $\mathbf{4}$ forebody, dorsal view $\mathbf{5}$ head, apical portion of pronotum and legs, frontal view $\mathbf{I} \mathbf{6}$ head, pronotum and antenna, dorsal view $\mathbf{I 7}$ elytra and abdomen, dorsal view $\mathbf{8}$ head and thorax, lateroventral view $\mathbf{9}$ apical portion of elytra, abdomen and legs, posterodorsal view. Scale bar: $1.0 \mathrm{~mm}$.

Etymology. Patronymic, the species is named to honor our colleague Vitalii I. Alekseev (Kaliningrad), great contributor to the knowledge of the fossil beetle fauna from Baltic amber. 


\section{Discussion}

In general, $A$. alekseevi sp. nov. can be characterized by the similar coloration and shape of the convex, shiny, and glabrous body, as in many species of Anthobium. The punctation of the forebody is poorly visible except in the lateral and basal portions of the pronotum and elytra; the median portion of the elytra bears longitudinal rows of punctures. The pronotum is shiny, and the microsculpture between punctures is missing. Similar punctation on the shiny forebody is specific for some East Asiatic species groups (e.g. gracilipalpe and nigrum). Similar to many species of the genus, the head of $A$. alekseevi sp. nov. has distinct median elevation and elongate grooves in front of the ocelli. Unfortunately, each latero-apical portion of the head is hidden by adjoining basal anttennomeres, so the presence and shape of an antocular identation are invisible. Usually, the antocular identation of Anthobium is variable in its shape: some species have distinct and semicircular notch as figured by Zanetti (1987: fig. 73a), and many species from Asia have a smooth or very indistinct notch. The shapes of the two preapical palpomeres of the maxillary palpus of $A$. alekseevi sp. nov. are similar to that of many Asiatic congeners. These palpomeres are approximately equal in their width, a characteristic shared in common with almost all the other species of the genus. The shape of the antennomeres of $A$. alekseevi sp. nov. is as usual for Anthobium, with the elongate antennomeres 5-10 recalling some species from Asia (e.g. Anthobium daliense Shavrin \& Smetana, 2017, species of the morchella group). The presence of a distinct mediobasal impression on the pronotum is similar to that of some Eastern Palaearctic species. On the contrary, the smooth margins of the elytra without distinct crenulation is suggestive of species from the Western Palaearctic Region. The microtomography of the specimen has not shown the presence of the aedeagus within the abdomen. Usually, species of Anthobium have the median lobe variable in width, narrow and long parameres, and a simple internal sac, sometimes with sclerotized additional structures.

Anthobium alekseevi sp. nov. has several significant morphological features that distinguish it from other known species of the genus, which led us to propose a new, separate species group for it. The first peculiar feature is the large body of the new species, which is roughly $5.4 \mathrm{~mm}$ long. So far, the largest specimens of Anthobium have been $4.75 \mathrm{~mm}$ long: Himalayan A. nigrum (Cameron, 1924) and Chinese A. puetzi Shavrin \& Smetana, 2017. On average, the body length of known species of the genus varies from 3.0 to $4.0 \mathrm{~mm}$, and the smallest species is the Chinese A. liliputense Shavrin \& Smetana, 2018, with specimens as small as $1.8 \mathrm{~mm}$ in body length. The second peculiar feature is the shape of subrectangular pronotum (Fig. 17). The pronotum of known species of Anthobium is distinctly transverse, and the minimum width of it in some species is usually 1.4 times as wide as long. The third peculiar one is the presence of a distinct median carina on the prosternum (Figs 11, 18). Most species of Anthobium have no similar structure on the prosternum. A similar structure can be found in some species of Arpedium, which have an indistinct carina-like elevation in the middle of the prosternum (see Campbell 1984: figs 14, 15). And finally, one of the interesting features of the new species is the presence of highly modified mesotibia, which possess 
a very large tooth in the middle (Fig. 7). Various modifications of the male tibia are frequent in some Anthophagini. A small subtriangular tooth or large triangular dilatation on inner margin of the protibia are known in some species of Anthobium (e.g. A. gracilipalpe (Champion, 1920); A. unicolor (Marsham, 1802), and A. atrocephalum (Gyllenhal, 1827); see Palm 1948: figs 155f, 156f), Arpedium (see Campbell 1984: figs 60, 64), Camioleum (see Shin and Ahn 2006: fig. 1) or Olophrum (e.g. Olophrum tadashii Watanabe, 1990; see Watanabe 1990: fig. 134). Some species have different modifications of the metatibia, such as the very long and acute, median, spine-shaped protrusion on inner side of each metatibia of Trichodromeus armatus (Cameron, 1941) (see Coiffait 1983: fig. 2M). Some species of Amphichroum are characterized by a deep and wide indentation in the middle of metatibia, sometimes with an indistinct median tooth (see Zanetti 1987: fig. 86). The inner sides of the pro- and mesotibia of Anthobioides have a large, convex swelling on their apical portion (see Campbell 1987: figs $1,34,35)$. In light of the examples above, $A$. alekseevi sp. nov. has one of the most unusual sexual modifications of the mesotibia within the tribe.

Species of Anthobium are strongly dependent on a temperate climate, living in forest litter and wet moss, and most commonly inhabit wet habitats near swamps and along banks of streams and rivers. Hypothetically, A. alekseevi sp. nov. may have lived in wet biotopes near rivers or swamps. A similar temperate-loving, extinct, and potentially rheophilous species, Geodromicus balticus Shavrin \& Yamamoto, 2019, was also described from Eocene Baltic amber.

\section{Acknowledgements}

We are grateful to Vitalii I. Alekseev (Kaliningrad, Russia) for the material, Kristaps Kairišs (Daugavpils, Latvia) for the providing of microtomographic images, and Giulio Cuccodoro (Genève, Switzerland) for helpful comments and suggestions. This study was partly supported by Grant-in-Aid for JSPS Fellows (JSPS KAKENHI Grant Number 20J00159) to SY from the Japan Society for the Promotion of Science (JSPS), Tokyo, Japan.

\section{References}

Cai C-Y, Huang DY (2013) Sinanthobium daohugouense, a tiny new omaliine rove beetle (Coleoptera: Staphylinidae) from the Middle Jurassic of China. The Canadian Entomologist 145: 496-500. https://doi.org/10.4039/tce.2013.33

Campbell JM (1984) A revision of the North American Omaliinae (Coleoptera: Staphylinidae). The genera Arpedium Erichson and Eucnecosum Reitter. The Canadian Entomologist 116: 487-527. https://doi.org/10.4039/Ent116487-4

Campbell JM (1987) Anthobioides pubescens, an unusual new genus and species of Omaliinae (Coleoptera: Staphylinidae) from Washington. The Canadian Entomologist 119: 10271042. https://doi.org/10.4039/Ent1191027-11 
Chatzimanolis S (2018) A review of the fossil history of Staphylinoidea. In: Betz O, Irmler U, Klimaszewski J (Eds) Biology of Rove Beetles (Staphylinidae) - Life History, Evolution, Ecology and Distribution. Springer, Cham, 27-45. https://doi.org/10.1007/978-3-31970257-5_3

Coiffait H (1983) Nouveaux staphylinides du Cachemire (Coleoptera). Annales de la Société entomologique de France (n. ser.) 19: 273-289.

Herman LH (2001) Nomenclatural changes in the Staphylinidae (Insecta: Coleoptera). Bulletin of the American Museum of Natural History 264: 1-83. https://doi.org/10.1206/00030090(2001)264<0003:NCITSI>2.0.CO;2

Hoffeins HW (2001) On the preparation and conservation of amber inclusions in artificial resin. Polskie Pismo Entomologiczne 70: 215-219.

Palm T (1948) Svensk Insekfauna. 9. Skalbaggar. Coleoptera. Kortvingar: Fam. Staphylinidae. Unterfam. Micropeplinae, Phloeocharinae, Olisthaerinae, Proteininae, Omaliinae. Almquist and Wiksells, Uppsala, 133 pp.

Ryvkin AB (1985) Zhuki semeistva Staphylinidae iz Iury Zabaikal'ia [Beetles of the family Staphylinidae from the Jurassic of Transbaikal]. In: Rasnitsyn AP (Ed.) Jurskiye nasekomyie Sibiri i Mongolii [Jurassic insects of Siberia and Mongolia]. Trudy Paleontologischeskogo Instituta, Akademia Nauk SSSR 211: 88-91. [in Russian]

Ryvkin AB (1990) Semeistvo Staphylinidae Latreille, 1802 [Family Staphylinidae Latreille, 1802] [pp. 52-66]. In: Rasnitsyn AP (Ed.) Pozdne-Mesozoiskie nasekomye vostochnogo Zabaikal'ia [Upper Mesozoic insects of eastern Transbaikalia], Trudy Paleontologischskogo Instituta, Akademia Nauk SSSR 239: 1-222. [in Russian]

Shavrin AV (2020) A revision of Eastern Palaearctic Anthobium Leach, 1819 (Coleoptera: Staphylinidae: Omaliinae: Anthophagini). IV. The atrocephalum and convexior groups, and additional species of the morchella, nigrum and reflexum groups. Zootaxa 4821(3): 401-434. https://doi.org/10.11646/zootaxa.4821.3.1

Shavrin AV, Smetana A (2017) A revision of Eastern Palaearctic Anthobium Leach, 1819 (Coleoptera: Staphylinidae: Omaliinae: Anthophagini). I. Gracilipalpe, morchella and nigrum groups. Zootaxa 4365: 1-39. https://doi.org/10.11646/zootaxa.4365.1.1

Shavrin AV, Smetana A (2018b) A revision of Eastern Palaearctic Anthobium Leach, 1819 (Coleoptera: Staphylinidae: Omaliinae: Anthophagini). II. fusculum group, and two additional species of the nigrum group. Zootaxa 4508: 451-506. https://doi.org/10.11646/ zootaxa.4508.4.1

Shavrin AV, Smetana A (2019) A revision of Eastern Palaearctic Anthobium Leach, 1819 (Coleoptera: Staphylinidae: Omaliinae: Anthophagini). III. Consanguineum, crassum and reflexum groups, and an additional species of the fusculum group. Zootaxa 4688: 451-482. https://doi.org/10.11646/zootaxa.4688.4.1

Shavrin AV, Yamamoto S (2019) Unexpected palaeodiversity of omaliine rove beetles in Eocene Baltic amber (Coleoptera, Staphylinidae, Omaliinae). ZooKeys 863: 35-83. https://doi. org/10.3897/zookeys.863.34662

Shin C, Ahn K-J (2006) Camioleum choi, a new species in the omaliine tribe Anthophagini (Coleoptera: Staphylinidae) from Korea. Zootaxa 1227: 57-62. https://doi.org/10.11646/ zootaxa.1227.1.3 
Watanabe Y (1990) A taxonomic study on the subfamily Omaliinae from Japan (Coleoptera, Staphylinidae). Memoirs of the Tokyo University of Agriculture 31: 55-391.

Wappler T (2005) The age of Baltic amber: could Eckfeld resolve this problem? In: Brothers D, Mostovski M (Eds) Fossils X3, $3^{\text {rd }}$ International Congress of Palaeoentomology with $2^{\text {nd }}$ International Meeting on Palaeoarthropodology and $2^{\text {nd }}$ World Congress on Amber and its Inclusions. Programme and Abstracts, $7^{\text {th }}$ to $11^{\text {th }}$ Feb 2005, Pretoria South Africa. University of Kwazulu-Natal, South African National Biodiversity Institute, Pretoria, 53 pp.

Zanetti A (1987) Fauna d'Italia. Coleoptera. Staphylinidae Omaliinae. Edizioni Calderini, Bologna, 472 pp.

Zanetti A, Perreau M, Solodovnikov A (2016) Two new fossil species of Omaliinae from Baltic amber (Coleoptera: Staphylinidae) and their significance for understanding the EoceneOligocene climate. Arthropod Systematics \& Phylogeny 74: 53-64. http://www.senckenberg.de/files/content/forschung/publikationen/arthropodsystematics/asp_74_1/03_ asp_74_1_zanetti_53-64.pdf 